\title{
Sustentabilidade em propriedades agrícolas familiares com produção de leite do cone sul de Rondônia (Brasil)
}

\section{Sustainability in family farming properties with cone sul de Rondônia milk production (Brazil)}

\author{
1 Diogo Mariano Hildefonso diogo.hildefonso@universo.univates.br \\ 2 Claudete Rempel \\ ${ }^{3}$ Magali Teresinha Quevedo Grave \\ 4 Claus Haetinger
}

\footnotetext{
1 Educador Físico, Mestrando em Ambiente e Desenvolvimento, Universidade do Vale do Taquari - Univates

2 Bióloga. Doutora em Ecologia. Docente do Centro de Ciências Médicas e dos Programas de Pós-Graduação em Ambiente e Desenvolvimento e em Sistemas Ambientais Sustentáveis, Universidade do Vale do Taquari - Univates.

3 Fisioterapeuta. Doutora em Ciências da Saúde. Docente do Centro de Ciências Biológicas e da Saúde, Universidade do Vale do Taquari - Univates.

4 Matemático. Doutor em Álgebra, Universidade do Vale do Taquari - Univates.
}

\section{Resumo}

A cadeia produtiva do leite no Brasil sofreu uma reestruturação a partir dos anos 1990. Todavia, nem sempre os pequenos produtores adotam ou compreendem esses novos padrões. Este estudo teve por objetivo identificar a sustentabilidade em propriedades agrícolas familiares que produzem leite, na região do Cone Sul-RO (Brasil), sob o tripé social, econômico e ambiental. Utilizou-se um sistema de avaliação por meio de procedimentos metodológicos próprios e validados, baseado em 23 indicadores e parâmetros específicos. Buscou-se caracterizar 36 das 67 propriedades dos municípios de Cabixi, Cerejeiras, Chupinguaia, Colorado do Oeste, Corumbiara, Pimenteiras e Vilhena. 0 índice de sustentabilidade estimado para a região foi de 0,64 , considerado regular, segundo a metodologia empregada. Em relação à sustentabilidade ambiental média, os parâmetros dejetos, reserva legal e usos da terra foram avaliados como ruins, o parâmetro água como regular e os demais como excelentes. A sustentabilidade social média apresentou o domínio relações sociais como excelente e os demais foram bons. Para a sustentabilidade econômica média, os parâmetros evolução patrimonial e serviços básicos foram considerados ruins, evolução tecnológica, gestão do empreendimento e sucessão familiar acabaram avaliados como regulares, e os demais foram bons, não havendo parâmetros inadequados ou excelentes.

Palavras-chave

Sustentabilidade. Produção leiteira. Indicadores de sustentabilidade. Agricultura familiar.

\begin{abstract}
The Brazilian milk production chain has been restructured since the 1990s. Although, small producers have not always fully or partially adopted or understood well these new patterns. This study aimed to identify the sustainability in small family dairy farms in the North brazilian Cone Sul - RO region, under the social, economic and environmental tripod. An assessment system was used through its own validated methodological procedures, based on 23 specific indicators and parameters. It was sought to characterize 36 of the 67 properties of the municipalities of Cabixi, Cerejeiras, Chupinguaia, Colorado do Oeste, Corumbiara, Pimenteiras and Vilhena. The estimated sustainability index for the region was 0.64 , considered regular, according to the methodology employed. Regarding the average environmental sustainability, the parameters waste, legal reserve and land uses were evaluated as poor, while the water parameter as regular and all others as excellent. Average social sustainability presented the social relations domain as excellent, whereas all others were considered as good. For the average economic sustainability, the parameters patrimonial evolution and basic services were considered bad, while technological evolution, enterprise management and family succession were evaluated as regular, and all others were estimated as good, with no inadequate or excellent parameters.
\end{abstract}

\section{Keywords}

Sustainability. Dairy production. Sustainability indicators. Family farming.

\section{Como você deve citar?}

HILDEFONSO, Diogo Mariano et al. Sustentabilidade em propriedades agrícolas familiares com produção de leite do cone sul de Rondônia (Brasil). Cadernos UniFOA, Volta Redonda, n. 43, p. 169-180, agosto 2020. 


\section{INTRODUÇÃO}

Diante dos problemas causados pelas variações climáticas, a superpopulação mundial e a escassez de alimentos, surge a necessidade de produzir mais e melhor (ALTIERI, 2010). A produção de alimentos demanda mais recursos como água, terras férteis, pessoas trabalhando na produção primária, entre outros e, mesmo com os avanços tecnológicos, há barreiras sociais e econômicas que envolvem o equilíbrio dos ecossistemas e que interferem na necessidade de alimentos diante do crescimento vertiginoso da população mundial (BEGOSSI, 2006).

A sustentabilidade, ao mesmo tempo que se processa no desenvolvimento dos países como indicador sob aspectos de análise tradicionais e contemporâneos, envolve o que se chama de desenvolvimento sustentável e, por meio dele, busca-se atender as necessidades do ser humano sem comprometer o equilíbrio sobre os recursos para as futuras gerações (BARBOSA, 2008). 0 pilar econômico relaciona-se aos assuntos de produção, distribuição e consumo, em que a eficiência produtiva e o crescimento econômico vislumbram recursos renováveis e diminuição da poluição. O pilar social diz respeito aos elementos que buscam a melhoria da qualidade de vida, da democracia e dos direitos humanos, sem afetar as relações de propriedade e recursos. A sustentabilidade ecológica envolve o equilíbrio e a manutenção do ecossistema, no qual empresas, sociedade e natureza cogitam diminuir impactos ambientais para a conservação e manutenção de recursos (LOURENÇO, 2017).

O desenvolvimento sustentável tem relevante importância no mercado brasileiro, estando diretamente ligado à geração de emprego e renda em todos os setores de atuação dentro da indústria, do comércio e dos serviços. No Brasil, existem discussões e experiências apontando que o desenvolvimento econômico o torna ambientalmente insustentável e socialmente injusto, fatores que envolvem o uso de recursos naturais e territórios por interesses próprios (PORTO; MILANEZ, 2009). A sustentabilidade tem forte relação com o desenvolvimento rural sustentável, envolvendo aumento de produção e renda, implicando na melhoria da qualidade de vida e de trabalho no espaço rural, gerando impactos práticos no meio ambiente (AHLERT; HAETINGER; REMPEL, 2017).

No mundo, os produtos lácteos ocupam a terceira posição no aumento de consumo entre os produtos de origem animal e, por isso, os países produtores de leite tentam acompanhar a demanda, aumentando a produção do leite in natura e seus derivados. A expectativa é de que a demanda por leite nos países em desenvolvimento cresça 25\% até 2025 (FAO, 2009). No âmbito dos produtores de leite, ainda existem os que executam suas tarefas de forma rudimentar, ignorando equipamentos tecnológicos que poderiam auxiliar e aumentar sua produtividade. Entretanto, com as transformações constantes no meio rural, pequenos agricultores estão buscando, mesmo com pouco capital, investir em melhores condições para realizar seu trabalho, o que proporciona um aumento na sua qualidade de vida (COSTA et al., 2011).

Na perspectiva das propriedades rurais, avaliar a sustentabilidade da unidade de produção também se tornou ponto crucial para a sobrevivência da família. Ehlers (2017) registra que a agricultura sustentável é um sistema que busca garantir a manutenção dos recursos naturais e da produtividade, avaliando os impactos ao meio ambiente e pensando a longo prazo em otimizar a produção das culturas, diminuindo ou extinguindo o uso de químicos; satisfazer as necessidades do homem com relação à alimentação; e atender as necessidades sociais das famílias rurais.

Utilizar indicadores de sustentabilidade contribui para entender os impactos gerados por processos produtivos, inclusive junto aos produtores de leite. Esses indicadores avaliam de forma simultânea resiliência do ecossistema, qualidade de vida e desempenho econômico. Entretanto, não basta avaliar, é preciso agir, medir e monitorar os índices, buscando a melhora contínua no âmbito da sustentabilidade (VEIGA, 2010). 
A produção leiteira no Brasil, em 1980, era de 11,2 bilhões de litros de leite anual; em 2014, foi de 35,1 bilhões de litros anual. Esse crescimento decorre de dois fatores: um refere-se ao aumento no número de vacas de ordenha, consequentemente, da capacidade produtiva; outro envolve o crescimento da produtividade dos animais brasileiros. O Brasil ocupa a quinta posição na produção leiteira mundial (MAIA et al., 2012; JUNG; MATTE JR., 2017). A produção de leite, segundo Nero, Viçosa e Pereira (2009), tornou-se uma atividade economicamente importante para o país, praticada principalmente por pequenos produtores. Essa atividade produtiva tem contribuído para que o setor agropecuário estabeleça mais renda e empregos aos produtores rurais e, por consequência, criam maior equilíbrio na produção do campo (CAMPOS; PIACENTI, 2007). Em se tratando de produção leiteira, a agricultura familiar é constituída por pequenos e médios produtores que representam a maioria dos agricultores no Brasil; segundo o Censo Agropecuário de 2006, são cerca de 4,3 milhões de unidades produtivas, correspondendo a $84 \%$ do número de estabelecimentos agropecuários do país (BRASIL, 2008).

No ranking nacional entre maiores estados produtores de leite, Rondônia ocupa o $9^{\circ}$ lugar, estando atrás de Minas Gerais, Paraná, Rio Grande do Sul, Goiás, Santa Catarina, São Paulo, Bahia e Pernambuco. Tem uma produção de 790 milhões de litros de leite anual, com 600.065 cabeças de vacas de leite (IBGE, 2016). De acordo com Alves (2016), Rondônia é considerado o maior estado produtor de lácteos da região Norte. A região do Cone Sul é o maior produtor leiteiro do estado de Rondônia, com produção diária de 41.131 litros, em 588 propriedades (ALVES, 2016).

Dessa forma, a presente pesquisa buscou analisar como está a sustentabilidade em propriedades agrícolas familiares com produção leiteira na região do Cone Sul de Rondônia, identificando e caracterizando-as em relação a aspectos do tripé social, econômico e ambiental. Justifica-se, outrossim, pela necessidade de entender sobre a sustentabilidade das unidades produtivas de leite, de forma que se possa auxiliar a promoção de ações visando retorno econômico para as famílias, contribuir para a conservação e preservação ambiental e melhorar a qualidade de vida das famílias nas propriedades rurais da referida região. No ambiente rural, há trabalhadores que não fazem o uso de instrumentos e tecnologias para melhorar seu processo produtivo; encontram-se ainda métodos manuais para as famílias rurais conseguirem a produção de leite (CYRNE, 2015). Por meio da visão da sustentabilidade, o crescimento dessas propriedades deve ocorrer de forma planejada, assegurando condições para a efetividade, eficácia e eficiência dessas famílias (MILARÉ, 2013). A sustentabilidade está relacionada a um conjunto de ideias, estratégias e atitudes que buscam um desenvolvimento ecologicamente correto, economicamente viável e socialmente justo (BORTOLI; REMPEL; BICA, 2014).

Construir indicadores que possam ser utilizados nos preceitos do agronegócio, que sejam de fácil compreensão e mensuração e contribuam para a avaliação nas propriedades no âmbito da sustentabilidade econômica, social e ambiental, pode permitir melhorias nas práticas e nos sistemas de produção, contribuindo para o desempenho socioeconômico e ambiental (BALDISSERA et al., 2007).

Dessa forma, este artigo tem como objetivo geral identificar a sustentabilidade ambiental, social e econômica das propriedades agrícolas familiares que produzem leite na região do Cone Sul-RO, considerando os aspectos sociais, econômicos e ambientais.

\section{PROCEDIMENTOS METODOLÓGICOS}

O estado de Rondônia (RO) é composto por 52 municípios, possui $237.590,547 \mathrm{~km}^{2}$ e 1.805 .788 habitantes (IBGE, 2010). Mais de $80 \%$ dos produtores de leite são pequenos produtores que atuam com falta de tecnologia no manejo do rebanho e o transporte é de baixa qualidade, diante dos concorrentes de outros estados. A Agência de Defesa Sanitária Agrosilvopastoril de Rondônia (IDARON, 2017, apud 
EMATER, 2016), revela um efetivo de 3.706 .705 bovinos leiteiros em todo o território, com produção diária de 2.209.107 litros. A produção leiteira nesse estado envolve o trabalho de, aproximadamente, 38.000 propriedades rurais, ocupando, aproximadamente, 100.000 trabalhadores, produzindo de $100 \mathrm{a}$ 300 litros de leite/dia nessas propriedades (SEBRAE, 2015). 0 estado de RO é o maior produtor leiteiro da região norte, $42 \%$ da produção da região, sendo o nono estado que mais produz no país, mais de 2 milhões de litros/dia (RONDÔNIA, 2017).

A região do Cone Sul de Rondônia possui uma área de $31.269,43 \mathrm{~km}^{2}$ e uma população de 137.534 habitantes, das quais 17.362 atuam na agricultura familiar, em 5.846 estabelecimentos rurais (CGMA, 2015). A região é composta por sete municípios: Colorado do Oeste, Cerejeiras, Cabixi, Chupinguaia, Corumbiara, Pimenteiras do Oeste e Vilhena. O município de Colorado do Oeste é o maior produtor de leite do Cone Sul e também do estado, com uma produção diária de 41.131 litros, em 588 propriedades. Já município de Pimenteiras do Oeste, fica na última colocação no ranking estadual, com produção média de 4.966 litros de leite por dia, em somente 306 propriedades (IDARON, 2017, apud EMATER, 2016; RONDONIAVIP, 2018). O município de Vilhena conta com 12.110 litros por dia, em 306 propriedades. Em Corumbiara, a produção é de 38.414 diários, em 512 propriedades. Chupinguaia produz 14.184 litros por dia, em 287 propriedades rurais, enquanto que Cabixi conta com 23.490 litros de leite por dia, em 364 áreas (IDARON, 2017, apud EMATER, 2016).

O estudo foi aplicado aos sete municípios do Cone Sul, totalizando 36 propriedades, as quais se enquadram como agricultores familiares e cujos produtores são proprietários das respectivas terras, em um universo de 67 propriedades. Para a seleção das propriedades, foram consideradas aquelas cuja renda familiar fosse baseada predominantemente na produção leiteira, podendo haver outras culturas que contribuam para a complementação da renda. Considerou-se, também, a rota de vacinas definida pela veterinária da EMATER. De posse da rota de vacinas, o entrevistador selecionou cinco ou seis propriedades de cada município, buscando-se atingir, aproximadamente, $50 \%$ das propriedades da região.

Para a coleta de dados, foi aplicado questionário do Sistema de Indicadores para Avaliação da Sustentabilidade de Propriedades Produtoras de Leite, desenvolvido por Ahlert (2015). Por meio desse sistema, buscou-se o gerenciamento das propriedades, atendendo os três pilares da sustentabilidade: econômico, ambiental e social, diagnosticando pontos frágeis e entraves e evidenciando pontos fortes e afırmativos que existem no âmbito da produção leiteira do Cone Sul/RO.

Os parâmetros econômicos se relacionam aos índices de: Produtividade e renda; Diversificação da renda; Evolução patrimonial; Grau de endividamento; Serviços básicos; Escolaridade e capacitação; Evolução tecnológica; Gestão do empreendimento e Sucessão familiar (QUADRO 1). 
Quadro 1 - Parâmetros de avaliação da sustentabilidade econômica

\begin{tabular}{|l|l|l|l|l|}
\hline \multirow{2}{*}{ Parâmetro } & Pontuação & Subparâmetro & Pontuação & $\%$ \\
\hline \multirow{4}{*}{ Produtividade e renda } & \multirow{4}{*}{20} & Capacidade de produção e renda bruta & 5 & \\
\cline { 3 - 5 } & & Relação custo/benefício da atividade & 5 & 20 \\
\cline { 3 - 6 } & & Pretensão para os próximos anos & 5 & \\
\cline { 2 - 6 } & Satisfação com a renda & 5 & 10 \\
\hline Diversificação da renda & 10 & Principais fontes de renda e participação & 10 & 10 \\
\hline Evolução patrimonial & 10 & Evolução patrimonial do imóvel rural & 10 & 10 \\
\hline Grau de endividamento & 10 & Valor da dívida em relação a renda & 10 & 10 \\
\hline Serviços básicos & 10 & Acesso a serviços básicos & 10 & 10 \\
\hline Escolaridade e capacitação & 10 & Escolaridade e capacitação para a atividade & 10 & 10 \\
\hline Evolução tecnológica & 10 & Evolução tecnológica & 10 & 10 \\
\hline Gestão do empreendimento & 10 & Gestão do empreendimento & 10 & 10 \\
\hline Sucessão Familiar & 10 & Sucessão familiar & 100 & 100 \\
\hline Totais & & & & 10 \\
\hline
\end{tabular}

Fonte: Adaptado de Ferreira et al. (2012, apud AHLERT; HAETINGER; REMPEL, 2017).

Já os parâmetros sociais, abordam quatro domínios da qualidade de vida: Domínio Físico; Domínio Psicológico; Domínio Relações Sociais; Domínio Meio Ambiente (WHOQOL, 1994; FLECK, 2000).

E os parâmetros ambientais envolvem os índices de Dejetos; Água; Área de Preservação Permanente (APP); Reserva Legal; Agrotóxicos e Fertilizantes; Declividade; Erosão; Queimadas e Usos de terra, seguindo a metodologia proposta por Rempel et al. (2012) (QUADRO 2).

Quadro 2 - Parâmetros de avaliação da sustentabilidade ambiental

\begin{tabular}{|c|c|c|c|c|}
\hline Parâmetro & Pontuação & Subparâmetro & Pontuação & $\%$ \\
\hline \multirow{3}{*}{ Dejetos } & \multirow{3}{*}{20} & Armazenamento do dejeto sólido & 10 & \multirow{3}{*}{20} \\
\hline & & Armazenamento do dejeto líquido & 5 & \\
\hline & & Destinação do dejeto animal & 5 & \\
\hline \multirow{2}{*}{ Água } & \multirow{2}{*}{10} & Fonte de água para consumo animal & 5 & \multirow{2}{*}{10} \\
\hline & & Fonte de água para consumo humano & 5 & \\
\hline \multirow{2}{*}{ APP } & \multirow{2}{*}{15} & Percentual de utilização das APPs & 10 & \multirow{2}{*}{15} \\
\hline & & Uso predominante na APP & 5 & \\
\hline Reserva Legal & 10 & Percentual de vegetação nativa para averbação em reserva legal & 10 & 10 \\
\hline \multirow{2}{*}{$\begin{array}{l}\text { Agrotóxicos e } \\
\text { Fertilizantes }\end{array}$} & \multirow{2}{*}{15} & Utilização de Fertilizantes químicos e agrotóxicos & 10 & \multirow{2}{*}{15} \\
\hline & & Armazenamento de embalagens de agrotóxicos & 5 & \\
\hline Declividade & 10 & Declividade do terreno & 10 & 10 \\
\hline Erosão & 5 & Evidências de solo erodido & 5 & 5 \\
\hline Queimadas & 5 & Evidências de queimadas & 5 & 5 \\
\hline Usos de terra & 10 & Diversidade de coberturas & 10 & 10 \\
\hline Totais & - & - & 100 & 100 \\
\hline
\end{tabular}

Fonte: Rempel et al. (2012, p. 51). 
Os indicadores seguem parâmetros nos quais se pondera a melhor situação (maior pontuação) reduzindo até a pior situação (pontuação menor), em que o somatório pode chegar a cem pontos, o máximo a ser alcançado por determinada propriedade, no caso de todos os aspectos analisados serem satisfatórios. Ainda, o índice pode variar no intervalo de 0 a 1, que se obtém por meio de uma função que atribui valor às variáveis do questionário, utilizando-se fatores de ponderação aos parâmetros em análise (REMPEL et al., 2012). Considera-se 0,6 o valor base/limiar para o desempenho sustentável (QUADRO 3).

Quadro 3 - Índice quantitativo de sustentabilidade

\begin{tabular}{|l|l|l|}
\hline Conceito & Índice de Sustentabilidade & Índice \\
\hline Excelente & Pontuação igual ou maior que 80 & $\mathbf{1 , 0 0}$ \\
\hline Bom & Pontuação igual ou maior que 60 & $\mathbf{0 , 8 0}$ \\
\hline Regular & Pontuação igual ou maior que 40 & $\mathbf{0 , 6 0}$ \\
\hline Ruim & Pontuação igual ou maior que 20 & $\mathbf{0 , 4 0}$ \\
\hline Inadequada & Pontuação menor que 20 & $\mathbf{0 , 2 0}$ \\
\hline
\end{tabular}

Fonte: Adaptado de Rempel et al. (2012, apud AHLERT, 2015).

De acordo com Rempel et al. (2012), os valores são organizados em cinco níveis de sustentabilidade, os quais são: Inadequado $(0 \vdash 0,20)$, Ruim $(0,20 \vdash 0,40)$, Regular $(0,40 \vdash 0,60)$, Bom $(0,60 \vdash$ $0,80)$, Excelente $(0,80 \vdash 1,00)$.

De posse dos dados individualizados das propriedades, foram determinados média aritmética simples, desvio-padrão em relação à média, valores máximos, valores mínimos, bem como a moda dos respectivos parâmetros, em um primeiro momento, por município e, posteriormente, do conjunto de todas as propriedades do Cone Sul investigadas neste estudo. Em seguida, foram elaborados gráficos e tabelas atinentes a esses dados.

\section{RESULTADOS E DISCUSSÃO}

O índice de sustentabilidade estimado para o Cone Sul foi de 0,64 , considerado regular, segundo a metodologia empregada. Os Quadros 4, 5 e 6 apresentam os resultados obtidos para as dimensões ambiental, social e econômica, respectivamente. 
Quadro 4 - Sustentabilidade ambiental média do Cone Sul

\begin{tabular}{|l|l|l|l|l|l|}
\hline Parâmetro & Média & Desvio-Padrão & Mínimo & Máximo & Moda \\
\hline Dejetos & 34,4 & 4,1 & 25,0 & 43,8 & 37,5 \\
\hline Água & 48,3 & 12,4 & 25,0 & 100,0 & 50,0 \\
\hline APP & 81,0 & 7,0 & 66,7 & 100,0 & 83,3 \\
\hline Reserva Legal & 27,8 & 40,0 & 0 & 100 & 0 \\
\hline Agrotóxicos e Fertilizantes & 89,2 & 11,8 & 58,3 & 100,0 & 100,0 \\
\hline Declividade & 83,3 & 21,5 & 25 & 100 & 100 \\
\hline Erosão & 83,3 & 26,7 & 0 & 100 & 100 \\
\hline Queimadas & 100,0 & 0,0 & 100 & 100 & 100 \\
\hline Usos de terra & 37,5 & 38,5 & 0 & 100 & 0 \\
\hline SUBTOTAL AMBIENTAL & 0,61 & 0,06 & 0,53 & 0,73 & 0,65 \\
\hline
\end{tabular}

Fonte: Dos autores (2019).

Quadro 5 - Sustentabilidade social média do Cone Sul

\begin{tabular}{|l|l|l|l|l|l|}
\hline Parâmetro & Média & Desvio-Padrão & Mínimo & Máximo & Moda \\
\hline Domínio Físico & 71,5 & 5,4 & 59,0 & 85,7 & 75,0 \\
\hline Domínio Psicológico & 77,9 & 8,9 & 58,3 & 88,0 & 87,5 \\
\hline Domínio Relações Sociais & 84,6 & 13,8 & 42,0 & 100,0 & 75,0 \\
\hline Domínio Meio Ambiente & 65,3 & 11,3 & 34,4 & 75,0 & 75,0 \\
\hline $\begin{array}{l}\text { SUBTOTAL } \\
\text { SUSTENTABILIDADE SOCIAL }\end{array}$ & 0,75 & 0,07 & 0,59 & 0,83 & 0,83 \\
\hline
\end{tabular}

Fonte: Dos autores (2019).

Quadro 6 - Sustentabilidade econômica média do Cone Sul

\begin{tabular}{|l|c|c|c|c|c|}
\hline \multicolumn{1}{|c|}{ Parâmetro } & Média & Desvio-Padrão & Mínimo & Máximo & Moda \\
\hline Produtividade e renda & 70,9 & 12,9 & 43,8 & 100,0 & 75,0 \\
\hline Diversificação da renda & 79,5 & 5,2 & 50,0 & 88,5 & 80,0 \\
\hline Evolução patrimonial & 20,8 & 25,0 & 0 & 100 & 0 \\
\hline Grau de endividamento & 75,0 & 27,4 & 0 & 100 & 100 \\
\hline Serviços básicos & 34,6 & 17,0 & 17,5 & 100,0 & 22,5 \\
\hline Escolaridade e capacitação & 63,9 & 16,7 & 49,0 & 100,0 & 49,0 \\
\hline Evolução tecnológica & 53,1 & 13,0 & 20,0 & 77,5 & 40,0 \\
\hline Gestão do empreendimento & 40,5 & 17,1 & 15,0 & 95,0 & 22,5 \\
\hline Sucessão familiar & 51,4 & 41,4 & 0 & 100 & 100 \\
\hline SUBTOTAL ECONÔMICO & 0,56 & 0,09 & 0,42 & 0,70 & 0,48 \\
\hline
\end{tabular}

Fonte: Dos autores (2019).

A média de qualidade de vida, quando analisados os quatro domínios juntos, é 73,1 (DP 7,1), o que indica uma 'boa" qualidade de vida, de acordo com a classificação proposta por Padrão e Sens (2009). No Gráfico da Figura 1, estão expressos as médias e os desvios-padrão de cada domínio avaliado, onde pode-se observar que o domínio das relações sociais apresenta a maior média. 
Figura 1 - Média e desvio-padrão dos escores de qualidade de vida dos produtores rurais participantes da pesquisa

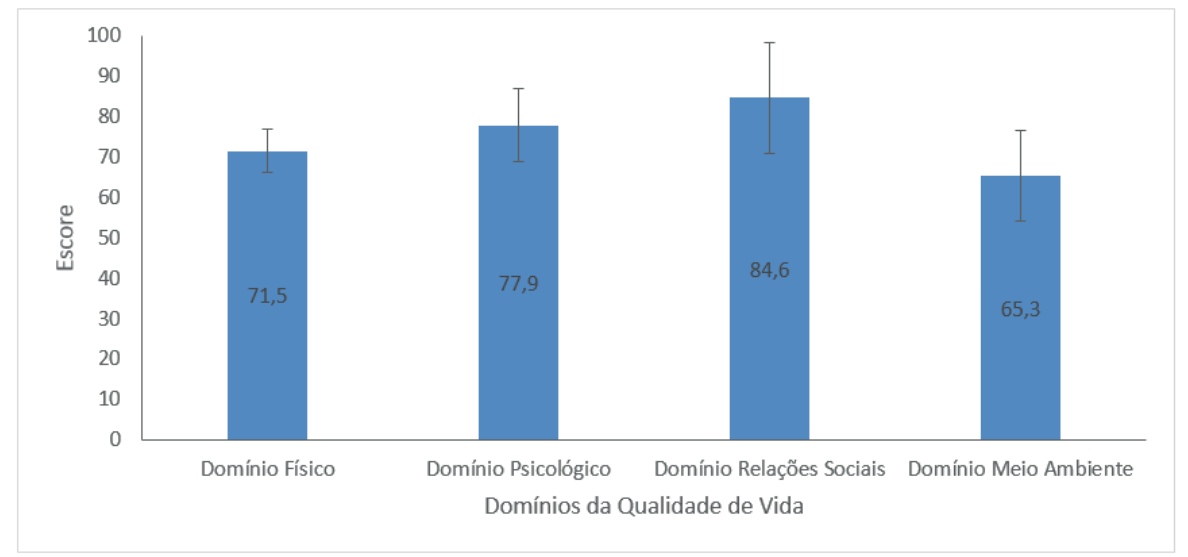

Fonte: Dos autores, 2019.

Percebe-se, a partir das entrevistas in loco, que, no Cone Sul, não parece haver uma fiscalização rigorosa por parte dos órgãos competentes, no que tange a aspectos como reserva legal e destinação de dejetos. Como a região é composta por pequenas propriedades em que se busca, de maneira rudimentar, tirar o máximo de proveito da terra, valendo-se de uma mão de obra bruta, com baixa escolaridade, há pouco interesse por capacitação e não há, em geral, um estudo planejado em relação ao uso de agrotóxicos e fertilizantes.

Muitas propriedades não possuem estrumeiras, nem para dejetos sólidos, nem para dejetos líquidos, e tanto currais como pastagens são precárias. A maioria das propriedades apresentou área de reserva legal abaixo de $5 \%$ da área total. Há propriedades que empregam mais de 6 tipos de coberturas da terra e muitas se dedicam exclusivamente à produção de leite, mesmo dispondo de área útil a outras atividades.

Percebe-se a falta de um Planejamento Ambiental, que poderia apresentar soluções para os conflitos entre as metas da conservação ambiental e do planejamento tecnológico. Por outro lado, e possivelmente devido ao desconhecimento dos aspectos acima citados, os resultados demonstram que os proprietários estão satisfeitos com a vida que levam no campo, em relação a aspectos como sua saúde, o ambiente onde moram, aparência física, disposição para o trabalho, situação financeira, lazer, satisfação sexual e ambiente físico do trabalho.

Observa-se a precariedade em inúmeros aspectos das propriedades, o pouco uso de tecnologias tanto na lida quanto do ponto de vista gerencial, o que se agrava pela dificuldade em obter financiamentos ou, quando obtidos, cumprir com a devolução dos mesmos, por falta de planejamento. Dessa forma, fica dificultado o investimento na ampliação patrimonial das propriedades, implicando em que a população estudada seja classificada como de classe baixa economicamente. Fator agravante e recorrente é a pouca atratividade da zona rural para os jovens filhos dos atuais produtores, que têm optado em migrarem para as cidades em busca de novas oportunidades, afetando a sucessão familiar como um todo.

Esse pouco interesse também pode estar atrelado à falta de serviços básicos na região do Cone Sul, tais como: saneamento, energia elétrica, água tratada, telefone, coleta de lixo, etc. Dessa forma, os produtores que lá permanecem já apresentam idade mais avançada, o que também implica em resistência e dificuldade em relação ao aprimoramento dos conhecimentos e à utilização de novas tecnologias aplicadas ao campo. 
No comparativo a outros estudos realizados a partir da metodologia proposta, considerando o estudo de Rempel et al (2012), os piores desempenhos ambientais no município de Arroio do Meio-RS foram também o de dejetos, juntamente com APP. Diferentemente do apontado no Cone Sul, nos dois municípios do Vale do Taquari-RS, segundo Bortoli, Rempel e Bica (2014), as estrumeiras são delimitadas e cobertas e, diferentemente do estudo supracitado, nestes não há problemas com as APPs, embora também haja problemas em relação aos dejetos, além do aspecto específico da erosão, em função do pastejo. Também nas propriedades estudadas no município de Anta Gorda-RS, o principal problema detectado foi o de dejetos e erosão, por conta de algumas não apresentarem estrumeiras e devido ao pisoteio dos animais, respectivamente, como apontam Maragnon e Rempel (2014), e Roloff et al. (2014), no município de Paverama-RS. As estrumeiras delimitadas e fechadas, como encontradas em algumas propriedades do Vale do Taquari-RS, não são uma prática comum, devido ao fato de não existir uma regulamentação para dejetos bovinos, a exemplo do que ocorre com os de suínos e aves. Todavia, na microbacia do Arroio da Seca, no RS, algumas propriedades não só possuem as estrumeiras fechadas, como deixam os dejetos descansarem por dois meses, para só então aplicá-los na adubação em suas lavouras, enquanto que outros adquirem esses dejetos de propriedades vizinhas, por não produzirem o suficiente (ZERWES, REMPEL SILVA da, 2018). Por outro lado, em relação aos aspectos sociais, os proprietários das propriedades estudadas no Cone Sul, embora sendo de faixa etária mais elevada, não apresentaram queixas em relação a dores de coluna, postura, etc, como verificado no município de Teutônia-RS, de acordo com Rempel, Haetinger e Sehnem (2013). Ao considerarmos os aspectos da gestão das propriedades, no Cone Sul se repete o já apontado por Cyrne, Haetinger e Rempel (2015) e Cyrne, Rempel, Haetinger e Eckhardt (2015), os quais registram o não uso de indicadores de gestão pelos proprietários no Vale do Taquari-RS, numa posição antagônica ao verificado na região da Galícia, Espanha, onde são utilizados sistematicamente ferramentas no acompanhamento dos custos da produção, da alimentação do gado, etc, mesmo que algumas propriedades ainda estejam em estágio inicial de implementação, como bem apontam Cyrne et al. (2015).

\section{CONSIDERAÇÕES FINAIS}

A partir da aplicação de indicadores para avaliação da sustentabilidade das propriedades produtoras de leite da região de Cone Sul de Rondônia, foi possível verificar que, de forma geral, pode ser considerada boa, sendo a dimensão social a mais bem avaliada $(0,75)$ e a dimensão econômica a mais mal avaliada $(0,56)$. Já a dimensão ambiental, apesar de enquadrada como boa, apresenta vários aspectos que merecem ser observados, em especial a forma de despejo dos dejetos e a cobertura da Área de Preservação Permanente.

\section{REFERÊNCIAS}

AHLERT, E.M. Sistema de indicadores para avaliação da sustentabilidade de propriedades produtoras de leite. 2015. 179f. Dissertação (Mestrado em Ambiente e Desenvolvimento) - Universidade do Vale do Taquari, Lajeado, 2015.

AHLERT, E.M.; HAETINGER, C.; REMPEL, C. Sistema de indicadores para avaliação da sustentabilidade de propriedades produtoras de leite. Revista Estudo \& Debate, Lajeado, v. 24, n. 2, 2017.

ALTIERI, M.A. Agroecologia, agricultura camponesa e soberania alimentar. Revista NERA, ano 13, $\mathrm{n}^{\circ}$. 16, p. 22-32, jan./jun. 2010. 
ALVES, José Luiz. Rondônia ocupa o $9^{\circ}$ lugar na produção de leite no País. Diário da Amazônia, 2016. Disponível em: https://www.diariodaamazonia.com.br/rondonia-ocupa-o-9o-lugar-na-producao-deleite-no-pais/. Acesso em: 20 ago. 2019.

BALDISSERA, B. M. Análise da sustentabilidade ambiental na empresa lavanderia ecológica. In: Congresso UFSC de controladoria e finanças e iniciação científica em contabilidade, 2, 2007, Florianópolis. Anais... Florianópolis: Universidade Federal de Santa Catarina, 2007.

BARBOSA, G.S. O desafio do desenvolvimento sustentável. Revista Visões, 4. ed., v. 1, n. 4, p. 1-11, 2008.

BEGOSSI, A. Ecologia Humana: Um Enfoque Das Relações Homem-Ambiente. Interciência, v. 18, n. 1, p. 121-132, 2006.

BORTOLI, J.; REMPEL, C.; BICA, J.B. Sustentabilidade ambiental de propriedades leiteiras localizadas em floresta ombrófila mista e em floresta estacional decidual, no Vale do Taquari/RS. Revista Gestão, Sustentabilidade e Negócios, v. 2, n. 1, p. 1-18, 2014.

BRASIL. Ministério da Agricultura. Censo Agropecuário 2006. Brasília: Ministério da Agricultura, 2008. Disponível em: http://www.agricultura.gov.br. Acesso em: 10 jan. 2018.

CAMPOS, K. C.; PIACENTI, C. A.. Agronegócio do leite: cenário atual e perspectivas. In: Congresso da Sociedade Brasileira de Economia, Administração e Sociologia Rural- SOBER, 45, Londrina - PR, 2007. Anais... Brasília-DF: SOBER, 2007. v. 45, p. 1-19.

CGMA. Coordenação-Geral de Monitoramento Atuarial. Perfil territorial: Cone Sul-RO. Brasília: MDA, 2015. Disponível em: http://sit.mda.gov.br/download/caderno/caderno_territorial_214_Cone\%20Sul\%20 -\%20RO.pdf. Acesso em: 20 fev. 2019.

COSTA, C.K.L. et al. Avaliação ergonômica do trabalhador rural: enfoque nos riscos laborais associados à carga física. Gestão da Produção, Operações e Sistemas. Bauru, n. 2, p.101-112, abr./jun. 2011.

CYRNE, C.C. da S.; HAETINGER, C.; REMPEL, C.; O (não) uso de indicadores de gestão em propriedades leiteiras do Vale do Taquari-RS. Estudo \& Debate, v. 22, n. 1, p. 128-142, 2015.

CYRNE, C.C. da S.; REMPEL, C.; HAETINGER, C.; BORTOLI, J.; O (não) uso de indicadores de gestão em propriedades leiteiras na Galícia - Espanha. Holos, v. 31, n. 5, p. 307-321, 2015.

CYRNE, C.C. da S.; REMPEL, C.; HAETINGER, C.; ECKHARDT, R.R.; Avaliação da gestão ambiental em pequenas propriedades produtoras de leite no Vale do Taquari a partir do uso da matriz importância $\mathrm{x}$ desempenho. Redes, v. 20, n. 2, p. 176-194, 2015.

CYRNE, Carlos Candido da Silva Cyrne. Indicadores de gestão em propriedades produtoras de leite do Vale do Taquari - um estudo comparativo com as propriedades da região da Galícia - Espanha. 2015. 220f. Tese (Doutorado em Ambiente e Desenvolvimento) - Universidade do Vale do Taquari, Lajeado, 2015.

EHLERS, E. O que é agricultura sustentável. São Paulo: Brasiliense, 2017. E-book. Disponível em: https:// books.google.com.br/books?hl=pt-BR\&lr=\&id=smgvDwAAQBAJ\&oi=fnd\&pg=PT2\&dq=agricultura+sust ent\%C3\%A1 vel\&ots=Ik9E4ZHf3F\&sig=nbhOj1 h9xxb6iNHwkOtuY3vnhE4\#v=onepage\&q=agricultura\%20 sustent\%C3\%A1vel\&f=false. Acesso em: 16 fev. 2019. 
EMATER. Relatório de gestão e atividades. Rondônia: Emater-RO, 2016.

FAO. The State of Food and the Agriculture: Livestock in the Balance. 2009. Disponível em:www.fao. org/ docrep/012/i0680e/i0680e.pdf. Acesso em: 26 mar. 2019.

FLECK, M. P. A. O instrumento de avaliação de qualidade de vida da Organização Mundial da Saúde (WHOQOL-100): características e perspectivas. Ciência e Saúde Coletiva], v. 5, n. 1, p. 33-38, 2000. Disponível em: http://www.scielo.br/pdf/Cone Sulc/v5n1/7077.pdf. Acesso em: 14 nov. 2018.

IBGE. Instituto Brasileiro de Geografia e Estatística. Censo Demográfico. 2010. Disponível em: https:// censo2010.ibge.gov.br/sinopse/index.php. Acesso em: 17 fev. 2019.

IBGE. Instituto Brasileiro de Geografia e Estatística. Pesquisa da Pecuária Municipal - PPM. IBGE, 2016. Disponível em: https://www.ibge.gov.br/estatisticas-novoportal/economicas/agricultura-epecuaria/9107-producao-da-pecuaria-municipal.html?=\&t=downloads. Acesso em: 5 maio 2018.

JUNG, C.F.; MATTE JUNIOR, A.A. Produção leiteira no Brasil e características da bovinocultura leiteira no Rio Grande do Sul. Ágora, Santa Cruz do Sul, v. 19, n. 1, p. 34-47, 2017.

LOURENÇO, M. Marketing sustentável e a educação ambiental. PluriTAS, n. 1, p. 1.25, 2017.

MAIA, G.B.S. et al. Produção leiteira no Brasil. BNDES Setorial, v. 37, p. 371-398, 2012.

MARAGNON, L. R.; REMPEL, C. Sustentabilidade ambiental em propriedades produtoras de leite do município de Anta Gorda/RS. Revista de Gestão, Sustentabilidade e Negócios, v. 2, n. 1, p. 164-183, 2014.

MILARÉ, É.. Direito do Ambiente. São Paulo: Revista dos Tribunais, 2013.

NERO, L.A.; VIÇOSA, G.N.; PEREIRA, F.E.V. Qualidade microbiológica do leite determinada por características de produção. Ciência tecnologia de Alimentos, Campinas, v.29, n.2, p.386-390, abr./jun. 2009.

PADRÃO, M. B.; SENS, Y. A. S. Quality of life of living kidney donors in Brazil: an evaluation by the short form 36 and the WHOQOL bref questionnaires. Clinical Transplantation, Nova Jersey, v. 23, n. 5, p. 621-627, 2009

PORTO, M.F.; MILANEZ, B. Eixos de desenvolvimento econômico e geração de conflitos socioambientais no Brasil: desafios para a sustentabilidade e a justiça ambiental. Ciência \& Saúde Coletiva, v. 14, n. 6, p. 1983-1994, 2009.

REMPEL, C. et al. Proposta Metodológica de Avaliação da Sustentabilidade Ambiental de Propriedades Produtoras de Leite. Tecno-Lógica, v. 16, n. 1, p. 48-55, jan./jun. 2012.

REMPEL, C.; HAETINGER, C.; SEHNEM, E.; Reflexões de idosos sobre as relações entre o trabalho rural, problemas de coluna e postura corporal. Estud. Soc. e Agric., v. 21, n. 2, p. 289-307, 2013.

ROLOFF, M.C.; REMPEL, C.; ECKHARDT, R.R.; Sustentabilidade ambiental de propriedades leiteiras do município de Paverama-RS. Tecno-Lógica, v. 18, n. 2, p. 60-68, 2014.

RONDÔNIA. Embrapa Rondônia leva tecnologias e informações para a Rondoleite. EMBRAPA Rondônia, 2017. Disponível em: https://www.embrapa.br/rondonia/busca-de-noticias/-/noticia/29818382/ embrapa-rondonia-leva-tecnologias-e-informacoes-para-a-rondoleite. Acesso em: 27 fev. 2017. 
RONDONIAVIP. Colorado se destaca em produção de leite em RO; outro município do Cone Sul ficou em último no ranking. 2018. Disponível em: http://www.jornalrondoniavip.com.br/noticia/geral/coloradose-destaca-em-producao-de-leite-em-ro-outro-municipio-do-cone-sul-ficou-em-ultimo-no-ranking/ colorado-do-oeste/. Acesso em: 20 fev. 2017.

SEBRAE. Diagnóstico do agronegócio do leite e derivados do estado de Rondônia. Porto Velho: SEBRAE, 2015.

VEIGA, J. E. Indicadores de sustentabilidade. Estud. av., São Paulo, v. 24, n. 68, p. 39-52, 2010.

WHOQOL. The development of the World Health Organization quality of life assessment instrument (the WHOQOL). In: ORLEY, J.; KUYKEN, W. (edit). Quality of life assessment: international perspectives. Heidelberg: Springer Verlag, 1994. p. 41-60.

ZERWES, C. M.; REMPEL, C.; SILVA, G. R.. Diagnóstico da sustentabilidade de propriedades rurais produtoras de leite na microbacia do arroio da seca. Revista Ibero-Americana de Ciências Ambientais, v. 9, n. 2, n.2, p.218-230, 2018. 